\title{
A reciprocidade e a instituição plural de mercados: um prisma para entender o papel histórico da Economia Social e Solidária
}

Reciprocity and the plural institution of markets: an approach to understand the historical role of the Social and Solidarity Economy

\author{
Luiz Inácio Germany Gaiger (1) \\ (1) Universidade do Vale do Rio dos Sinos
}

\begin{abstract}
The article aims at demonstrating that one of the main historical roles of the Social and Solidarity Economy is the preservation of life systems and socioeconomic organizations distinct from the market economy. The empirical elements in favor of this thesis come from studies in various regions and continents, while their theoretical foundations are based on the seminal contributions of Karl Polanyi and Marcel Mauss, which allow us to understand how a plurality of principles determines the performance of companies and structures economic systems. It is argued that the Social and Solidarity Economy is opposed to the primacy of the principle of exchange, pillar of market societies, by activating the principle of reciprocity, upon which other processes of production and circulation of goods develop. Doing so, it gives rise to a multiplicity of markets, undoing the appearances of a single market and the belief in its inevitability.
\end{abstract}

\section{Keywords}

economy, solidarity, reciprocity, market, Karl Polanyi, Marcel Mauss.

JEL Codes B55, P13, P51, Z13.

\section{Resumo}

Este artigo objetiva demonstrar que um dos papéis históricos da Economia Social e Solidária está vinculado à preservação de sistemas de vida e organizações socioeconômicas distintas da economia de mercado, ao se constituírem como sociedades de pessoas, lastreadas em relações sociais vinculantes. Os elementos empíricos em favor dessa tese provêm de estudos em diversas regiões e continentes, enquanto seus fundamentos teóricos assentam-se nas contribuições seminais de Karl Polanyi e Marcel Mauss, as quais nos permitem entender como uma pluralidade de princípios determina a atuação de empresas e estrutura os sistemas econômicos. Argumenta-se que a Economia Social e Solidária se contrapõe à primazia do princípio de intercâmbio, base da sociedade de mercado, ao acionar o princípio da reciprocidade, com o qual institui outros processos de produção e circulação de bens. Assim, dá origem a uma multiplicidade de mercados, desfazendo as aparências de um mercado único e a crença em sua inevitabilidade.

\section{Palavras-chave}

economia, solidariedade, reciprocidade, mercado, Karl Polanyi, Marcel Mauss.

Códigos JEL B55, P13, P51, Z13. 


\section{Introdução}

Desde o século XIX, observa-se em diversos países a presença de organizações econômicas ancoradas em laços de reciprocidade e em práticas de cooperação. Suas atividades de produção de bens ou de prestação de serviços atendem precipuamente a necessidades e aspirações do conjunto de indivíduos envolvidos, conferindo-lhes assim um caráter eminentemente social. Por essa via e em paralelo ao domínio da economia de mercado, estratégias associativas, cooperativas e mutualistas buscaram assegurar condições de vida a importantes contingentes e, ademais, mantiveram vigentes princípios de organização do trabalho e de circulação da riqueza distintos da racionalidade intrínseca à lógica do capitalismo. Na esteira dessas iniciativas, configurou-se em países do Norte a Economia Social, umbilicalmente vinculada ao movimento operário em seus primórdios, mas também levada à frente para atender expectativas e demandas de agricultores familiares, consumidores e cidadãos em geral. Iniciativas similares reproduziram-se ao Sul, com variadas designações, destacando-se a Economia Solidária no contexto latino-americano, na qual ênfase é dada ao caráter participativo, autogestionário e cooperativo, quanto ao trabalho e aos meios de produção dos empreendimentos. Nas últimas décadas, elas ganharam impulso em escala global, conformando novas frentes de ativismo socioeconômico e novos formatos institucionais, do que resultou a designação usual, embora variável, de Economia Social e/ou Solidária. ${ }^{1}$

Em que pesem suas descontinuidades e seus momentos de refluxo, essas iniciativas não enveredaram inexoravelmente para sua dissolução. Ao contrário, elas se diversificaram e ressurgiram sob várias formas, tanto para reeditar modelos já institucionalizados pela Economia Social na Europa, no Canadá e em países da América do Sul como Argentina e Colômbia, quanto para demonstrar que seus princípios vicejam em muitas outras formas de economia, estando por vezes no âmago de sistemas de vida centenários, ditos pré-capitalistas, em vários recantos do globo. Sua perseverança e seus desdobramentos atuais conduziram, entre outros, a postular a existência de um paradigma cooperativo, cuja longevidade explica-se por sua consistên-

1 As designações variam de acordo com a trajetória e a conformação desse campo de práticas em cada contexto regional ou nacional, sem interferir significativamente nas questões tratadas neste artigo. Para uma discussão conceitual, ver Cattani et al. (2009); para uma visão ampla, Defourny e Nyssens (2017); em relação ao contexto latino-americano, Gaiger et al. (2019). 
cia e por sua insistência utópica, assim como por seu pragmatismo e sua abertura diante das mudanças constantes nas sociedades em que prosperou (Namorado, 2007). Na prática dos fatos, as iniciativas de cooperação sofreram distorções, conheceram reveses e períodos de estagnação. Ainda assim, sua história, cujo elã reflete-se hoje na adição do adjetivo "Solidária" à Economia Social, exprime simultaneamente a impossibilidade e a recusa, por parte de inúmeras categorias sociais, povos e comunidades, de viverem encerrados em uma lógica fundada em condutas utilitárias cujo pressuposto, em particular no campo das atividades econômicas, é a renúncia a formas de vida alicerçadas no cultivo de vínculos sociais. ${ }^{2}$

A magnitude dos interesses contrários atuantes no ambiente econômico - aliada à força de hábito de não considerarmos a economia senão na ótica do mercado e supormos motivações utilitaristas, em primeiro lugar, como estando subjacentes à conduta econômica - representa uma considerável barreira ao reconhecimento dessas variadas iniciativas, mas não um entrave definitivo e intransponível. Como é possível alterar esse quadro e visualizar alternativas, com os devidos fundamentos? Em que medida a Economia Social e Solidária constitui uma dessas vias? Adentrando o terreno da economia a partir de suas relações com a sociedade, tencionamos aportar algumas respostas a essas questões.

Nosso propósito será principalmente demonstrar que a Economia Social e Solidária promoveu e preservou, ao longo do tempo, sistemas de vida e organizações socioeconômicas cujos fundamentos estruturais se distinguem da economia de mercado, em razão de princípios estruturantes que lhes são próprios. Nisto estima-se residir a sua principal contribuição: em razão de sua natureza sui generis, a Economia Social e Solidária subordina suas práticas econômicas ao fato de se constituírem a partir e em função de comunidades e associações de pessoas, lastreadas em relações sociais vinculantes, o que a conduz a contrapor-se à lógica da economia de mercado, a alimentar e alimentar-se de formas socialmente vinculantes de organização das atividades habitualmente classificadas de econômicas. Os principais argumentos teóricos dessa linha de entendimento provêm das contribuições magistrais de Karl Polanyi, que nos permitem entender

2 O Utilitarismo surgiu como uma corrente filosófica (Mulgan, 2014), cuja evolução no plano das ideias e em suas aplicações práticas rapidamente se diversificou e deparou-se com severas críticas, dado o reducionismo que impõe à natureza e à conduta humana e por seu caráter axiomático indemonstrável (Sen, 1999). 
como uma pluralidade de princípios determina a lógica das organizações e estrutura os sistemas econômicos. Sob esse prisma, veremos, a Economia Social e Solidária contrapõe-se à supremacia do princípio de intercâmbio, do qual deriva a economia de mercado. Ela aciona, em seu lugar, o princípio da reciprocidade, com o qual institui processos econômicos socialmente orientados. Por essa via, promove múltiplas formas de mercado, desfazendo as aparências de um mercado único, e desmente a crença - para Karl Polanyi, obsoleta - na inevitabilidade da forma atualmente dominante de mercado como esteio da vida econômica e da sociedade como tal. Ainda, a interpretação do princípio de reciprocidade, nos termos propostos, nos conduzirá a destacar as convergências entre Karl Polanyi e Marcel Mauss (2003), cuja teoria da dádiva remete ao mesmo princípio de valorização dos laços sociais, e a reposicionar a esfera econômica no interior de um arcabouço social envolvente, com suas normas e estruturas.

$\mathrm{Na}$ primeira seção, indicaremos como as economias empíricas decorrem de um processo instituído que as mantém imersas socialmente, com graus variáveis e no geral escassos de autonomia em relação às normativas que emanam dos seus entornos sociais. Esse processo de instituição não se opera num suposto reduto de fatos econômicos; tampouco, se faz simplesmente por supressão de padrões econômicos anteriores, mas via recombinações em sua estrutura interna ou devido ao desenvolvimento concomitante de novos padrões. Na segunda seção, trataremos de explicar por quais razões a economia de mercado, sob o impulso da lógica capitalista de acumulação, representa um caso histórico à parte, que foge tendencialmente a essa regra. Isto posto, na terceira seção as relações entre as formas de economia e a sociedade ficarão mais bem apreendidas a partir da noção de pluralidade econômica, o que demanda categorias de análise dos níveis e formas de integração entre princípios e padrões econômicos. Uma vez estabelecido esse quadro, o exame do papel cumprido pelo princípio da reciprocidade, compreendido igualmente em suas relações com o paradigma da dádiva, abrirá caminho na quarta seção para dimensionar o papel e a relevância histórica da Economia Social e Solidária. Sua incidência fundamental diante da hegemonia do mercado não reside em sua capacidade de equiparar-se ou concorrer com ele, mas sim de revigorar outros princípios de organização da vida coletiva. Exemplos de sua presença, como expressão e fator de impulsão da reciprocidade, evidenciarão como a Economia 
Social e Solidária (ESS) ${ }^{3}$ institui formas distintas de economia, ao mesmo tempo que "desmercantiliza" o mercado e nos mantém protegidos da falácia de sua necessária onipresença e autossuficiência. O texto se concluirá com algumas reflexões sobre a atualidade do princípio da reciprocidade.

Este artigo, portanto, desenvolve um enfoque teórico-conceitual sobre as questões propostas, sem desconhecer outras possibilidades explicativas. Sua abordagem sistemática requereria mais tempo, ainda que se referisse a contribuições e controvérsias de um campo específico, a exemplo da Nova Sociologia Econômica, em cuja órbita situam-se vários autores citados. Preferimos então manter-nos na rota do fio argumentativo proposto, que sintetiza resultados de incursões teóricas e de estudos sobre realidades de várias regiões e continentes, em diferentes épocas. ${ }^{4}$

\section{A instituição social da economia}

Ao longo da história, as atividades de produção e de circulação dos bens e serviços estiveram, em regra, imersas na vida social, sem constituírem uma esfera determinada por normas próprias, à parte, ao contrário do que vivenciamos em nossa época. A esse respeito não tiveram dúvidas alguns dos precursores da ciência moderna designada de Economia, como Adam Smith (Sen, 1999) e Karl Marx (Levine et al., 1989), ou clássicos da Sociologia como Max Weber, Émile Durkheim (Raud-Mattedi, 2005) e Georg Simmel (Caillé, 1996). Tampouco hesitam sobre isso as correntes atuais não estritamente individualistas ou utilitaristas (Wacquant; Calhoun, 1991; Caillé, 1996; Cattani et al., 2009), ou os enfoques alinhados à Nova Sociologia Econômica (Laville, 1997), sem falar da escola antiutilitarista nas ciências sociais (Godbout, 1999).

Ainda assim, o caráter da inserção da economia na sociedade, ou do seu imbricamento social, deu margem a várias interpretações. Para alguns, a imersão social da economia significa que a atividade econômica sempre se

3 Doravante, utilizaremos essa sigla.

4 Não há espaço aqui para repertoriar tais estudos, desenvolvidos ao longo dos últimos 25 anos, desde 2000, graças à Bolsa de Produtividade e auxílios recebidos do Conselho Nacional de Desenvolvimento Científico e Tecnológico (CNPq). Diga-se, ao menos, que se endereçaram ao fulcro teórico que embasa este artigo (Gaiger, 2016), à compilação de trabalhos de especialistas sobre realidades diversas do Sul e do Norte (Gaiger; Santos, 2017) e a uma análise panorâmica mais recente, especialmente do contexto latino-americano (Gaiger et al., 2019). 
realiza no interior de relações sociais, sendo afetada pela dinâmica dessas interações (Granovetter, 1985): os agentes econômicos são induzidos a tecer vínculos sociais como forma de lograrem resultados econômicos, mas fazem isso também porque se orientam por outros objetivos, como sociabilidade, aprovação social, identidade e status. No seu fazer econômico, observa-se a influência das relações interpessoais e de fatores imponderáveis, como a confiança. Há vasos comunicantes entre a esfera econômica e as demais, atribuíveis tanto às relações sociais que incidem sobre os agentes quanto à influência exercida pelo contexto cultural e político mais amplo (Granovetter, 1999).

Noutra vertente, a imersão social da economia significa que o funcionamento dos mercados deve ser controlado para que não conduza a excessos e desequilíbrios, ou para que se mantenha estável e garanta seus prometidos benefícios. Da necessidade desse tipo de intervenção já não restaria dúvida, como demonstra o Prêmio Nobel da Economia de 2001, Joseph Stiglitz: em tempos neoliberais fica patente a urgência de libertar-nos da venda que nos impede de perceber a natureza politicamente deliberada da economia dita livre, assim como o fato de responder antes de tudo aos interesses das classes detentoras do capital. Ele completa: "nunca houve um sistema de mercado verdadeiramente livre, autorregulado. Nas suas transformações, os governos dos atuais países industrializados desempenharam um papel ativo, não apenas protegendo suas indústrias por meio de tarifas, mas também promovendo novas tecnologias (...). Mesmo hoje, protecionismo e intervenções governamentais estão vivos e bem" (Stiglitz, 2001, p. xiii). É também um fato histórico que, desde os primórdios do século XIX, movimentos sociais em diferentes sociedades têm lutado contra a liberdade outorgada à moderna economia de mercado, dada a sua tendência inata a desprender-se dos fatores que restringem a produção e circulação crescente de mercadorias e a impor sua lógica própria à estrutura e à vida social.

Nas formulações de Karl Polanyi, entretanto, a premissa da inserção social da economia significa em seu sentido mais incisivo que a economia não possui fins próprios, autodeterminados; ela não é por si mesma senão um meio (como o próprio dinheiro), um modo de viabilizar realizações humanas - embora tais realizações possam passar ao largo do território dito "econômico", salvo no caso particular da sociedade de mercado. Por isso, dizer que a economia está entrelaçada à vida social significa que ela não 
deriva de leis próprias, de finalidades independentes de parâmetros socioculturais, ou materializando uma espécie de economia natural, como um desfecho inevitável da repetição de condutas individualistas que seriam intrínsecas aos seres humanos. Significa admitir que a economia não é mais que um termo utilizado em nossa época para evocar mentalmente uma dimensão particular da vida coletiva. Essa dimensão resulta de um processo historicamente instituído (Polanyi, 1957) pelo qual cada sociedade determina como se ocupará da produção e circulação dos seus meios de subsistência, de acordo com o sentido que atribui a eles e aos desdobramentos dessas atividades que julgar desejáveis.

O formato desse processo, isto é, sua forma institucional e os motivos que o fazem funcionar não são determinados por nenhum único fator, seja natural ou humano, mas são resultantes de vários niveis interdependentes da existência humana, ecológico, tecnológico, social e cultural (Pearson, 1957, p. 326).5

As relações econômicas entre pessoas, grupos e coletividades, dependem de valores reconhecidos, de normas arbitradas e dos meios de levá-las à prática. Algo óbvio, mas esquecido: as sociedades criam e controlam os atos econômicos praticados em seus territórios. A julgar pelo conhecimento a respeito, na maior parte dos casos elas não postularam que o homem se comportaria como o "lobo do homem" e não encontraram muitas insistências em contrário. Mesmo a instauração do sistema econômico moderno, movido pela concorrência fria entre agentes econômicos, não se explica por uma compulsão humana irrefreável, mas por uma ação deliberada de agentes de classe, com auxílio decisivo do Estado, para submeter domínios cada vez mais vastos da vida social aos desígnios dos mecanismos de mercado. Desde o século XIX, foi precisamente contra as repercussões trágicas desses fatos que se ergueram as vozes e as iniciativas práticas que vieram a conformar a ESS.

As instituições econômicas devem ser compreendidas como entidades socialmente construídas, nas quais os processos correlatos são codificados e internalizados na cultura, propiciando estabilidade e fluidez à economia (Plociniczak; Maucourant, 2009, p. 145-146). Isto acarreta uma imbricação insolúvel entre a economia e os elementos sociais e culturais, visível na expressão "cultura de mercado" e nos estudos sobre a formação e a influência das mentalidades econômicas. É então arbitrária e etnocêntrica a 5 Tradução feita pelo autor. No caso de textos já traduzidos para o português, fez-se uma comparação com as fontes originais, aportando-se ajustes quando necessário. 
separação entre as atividades econômicas e as demais, dado que tais fronteiras costumam ser fluídas e cambiantes, senão inexistentes. Ademais, os comportamentos econômicos possuem uma clara dimensão política, uma vez que sua ocorrência e sua recorrência supõem normas sancionadas e legitimadas. ${ }^{6}$ Não sendo espontâneas, as instituições econômicas tampouco são universais ou perenes. ${ }^{7}$ Como enfatizou Karl Polanyi, ao contrário dos nossos hábitos e crenças, a estrutura institucional da economia em geral não obrigou os indivíduos a economizar, no sentido comum de gastar menos tempo, recursos ou dinheiro (Polanyi et al., 2012, p. 84).

Em suma, a economia real encontra-se imbricada em instituições econômicas e não econômicas (Polanyi, 1957, p. 250), ${ }^{8}$ que propiciam continuidade e previsibilidade em relação à conduta dos agentes. Ao mesmo tempo, indicam o teor processual tanto da economia quanto das demais dimensões da vida coletiva (Plociniczak; Maucourant, 2009). De um lado, existem condições instituídas: emprestar a juros já foi proibido, jogos de azar ainda o são, amiúde; contratos leoninos são censurados, conforme julgar a moral de cada sociedade. De outro lado, existem condições instituintes: não basta que indivíduos atuem similarmente e engendrem um tipo de comportamento para que ingressem em um tipo de economia. Como veremos, uma economia de reciprocidade - e todas as que não sejam definidas pelo mercado - não se cria nem evolui sem laços comunitários, estamentais, corporativos ou associativos, capazes de gerar um padrão de relações. Por sua vez, atos individuais de troca, ou de intercâmbio, apenas contribuem para formar preços se existirem mecanismos sistematicamente definidores de preços, somados a uma tendência geral a que bens e serviços sejam vendidos e comprados:

Atos individuais de permuta ou troca - esta é a verdade - não levam, como regra, ao estabelecimento de mercados em sociedades nas quais prevalecem outros princípios de comportamento econômico. Tais atos são comuns em quase todos os tipos

6 Um exemplo disso é o padrão-ouro, cuja influência sobre a economia nacional e internacional foi inegável, sem ele próprio originar-se dos movimentos espontâneos da economia, mas sim de uma decisão arbitrada por um conjunto de nações, justamente para dirigir e liberar os fluxos econômicos sob certas condições.

7 Um caso notório é a moeda, cujo uso nem sempre teve finalidades ou mesmo conotações econômicas, demonstrando que o ato de regular e mesmo de medir as interações sociais não nos remete invariavelmente à economia (Polanyi, 1968, p. 175-205; 1977, p. 97-121).

8 Como salientam Maucourant e Plociniczak (2009), a abordagem polanyiana vai além da Nova Economia Institucional (NEI), uma vez que para essa escola as instituições são complementares ao mercado (ou à economia) e esse, como tal, não é considerado uma instituição. Os determinantes extraeconômicos do mercado são vistos por ela como fatores ad hoc. 
de sociedade primitiva, mas são considerados como incidentais uma vez que não atendem às necessidades da vida. Nos vastos sistemas antigos de redistribuição, atos de permuta tanto quanto mercados locais eram uma constante, mas não mais do que um traço subordinado (Polanyi, 2001, p. 64).

Para que ações individuais tenham a força necessária para instaurar um padrão econômico próprio, condições supraindividuais são requeridas, implicando a bem dizer uma "parafernália" (Arensberg et al., 1957, p. xvii) de instituições que encarnem e disciplinem as práticas através de legislações, autoridades e códigos de conduta; do contrário, atos econômicos inovadores provavelmente serão vistos como anomalias ou transgressões intoleráveis. Há, portanto, uma diferença entre princípios econômicos como tais, que operam com fins específicos ou particulares, e princípios com poder de integração, que funcionam como esteio de um determinado padrão de economia, garantido por meio de instituições que lhe conferem unidade e estabilidade.

O que designamos de economia pública ou estatal, para Karl Polanyi (1977, p. 40-42) constitui a manifestação contemporânea de um padrão instituído de diversas formas ao longo da história, com base em um princípio comum, integrador: parte da riqueza disponível é legitimamente concentrada nas mãos de uma autoridade central (via impostos etc.) que, a seu turno, garante sua redistribuição de acordo com critérios legitimados socialmente, em ações de defesa, construção de infraestrutura, atividades religiosas, suntuárias etc. Noutro caso, o que está por trás das retribuições simétricas e repetidas entre indivíduos (no interior de organizações), categorias sociais (como nas sociedades camponesas) ou entre nações (cooperação internacional) é o princípio da reciprocidade - o mesmo que modela o funcionamento das organizações da ESS, que assim configura um padrão de economia específico, mesmo sem exercer um papel dominante.

Atos de troca, monetária ou não, realizados para satisfazer interesses das partes que transacionam, são uma prática regida pelo princípio do intercâmbio. Mas até que esse princípio se generalize, torne-se um vetor de integração e institua uma economia de intercâmbio, vai uma larga distância. $\mathrm{Na}$ falta dessa distinção, cria-se uma sinonímia indevida entre o princípio de intercâmbio e o mercado, que corresponde a um padrão econômico e cuja estrutura depende da forma como o intercâmbio, em contextos historicamente situados, passa a integrar a economia, de forma mais ou menos abrangente e exclusiva. Na maior parte das sociedades, a economia não foi integrada pelo intercâmbio, mas sim por outros princípios; mesmo haven- 
do trocas, fato comum a muitas delas, não havia um padrão de mercado ou, havendo, ele estava subordinado a outro princípio, a quem cabia o papel de integração. Ou seja: na maior parte das sociedades históricas, não tivemos uma economia de mercado.

\section{A autonomização da economia de mercado}

A recorrência de sociedades sem mercado, cujas instituições econômicas não derivam do princípio de intercâmbio, ficou bem demonstrada nas pesquisas históricas da equipe de Karl Polanyi. Um dos conceitos elaborados no estudo de civilizações da Mesopotâmia, África, América Central e costas do Mediterrâneo é o porto de comércio (Polanyi, 1963). Ele confirma um aspecto central daquelas investigações: as práticas de comércio, ou de trocas regulares de bens entre povos e civilizações, ocorreram em geral na ausência de um sistema de mercado instituído como padrão dominante. Não há razões para tomar esse último como desfecho evolutivo no qual fatalmente teriam desembocado as práticas antigas de troca, nem para ver na ausência de um tal sistema a causa de sua decadência, após séculos de funcionamento. Mesmo em importantes centros comerciais, o intercâmbio era algo ocasional e secundário: havia trocas, praças de mercado, espaços para permuta e barganha, mas não um sistema geral de preços flutuantes, do qual dependeriam os negócios entre agentes supostamente movidos por um afã de obter vantagens monetárias ou materiais, repetidamente. Ao contrário, às vezes a condução de tais entrepostos era fundamentalmente administrativa e visava proteger a sociedade local do contato excessivo com outros sistemas econômicos. Evitava-se expor sua coesão social a riscos desestabilizadores, sem renunciar às vantagens da troca de bens de longo curso (Graslin; Maucourant, 2005).

Historicamente, o comércio integrou sistemas econômicos amplos, baseados tanto na reciprocidade quanto na redistribuição. Ele podia propiciar a troca de mercadorias e dispor de alguma autonomia, mas não estava compulsoriamente motivado por expectativas individuais de ganhos pecuniários crescentes. Ou seja, o princípio e as práticas de intercâmbio estiveram presentes no comércio, sem por isso funcionarem como fator integrativo (Polanyi, 1977, p. 81-96). Seria um equívoco tomar o intercâmbio e o mercado como realidades idênticas e onipresentes ou, como já dito, explicar 
por sua ausência as deficiências ou imperfeições das economias não plenamente mercantis. Esse hábito corrente foi questionado por Karl Polanyi:

afirma-se a presença virtual de um sistema de mercado em toda sociedade, a despeito de que tal sistema esteja empiricamente presente ou não. Toda a economia humana deve então ser vista como um potencial mecanismo de oferta-demanda- preço e, em consequência, explicar os processos reais, quaisquer que sejam, nos termos dessa hipostasia (Polanyi et al., 2012, p. 84).

Sendo assim, a questão consistiria em saber em quais condições o princípio do intercâmbio instituiu a economia em que vivemos. Isso não ocorreu como um processo inevitável, como fruto natural do progresso ou de algum consenso racionalmente estabelecido e irretorquível. A nossa economia de mercado tampouco resultou de um crescimento ou transformação dos mercados locais ou nacionais preexistentes. Ela apareceu no século XIX, no bojo de uma transformação social complexa e de forma inusitada, em parte graças à intervenção consciente do Estado, somada à expansão do comércio exterior, vindo assim a afetar drasticamente as práticas de comércio conhecidas. ${ }^{9}$

Como a economia pôde estruturar-se sob a égide do intercâmbio, ser por ele impulsionada e, a seguir, entronizá-lo como padrão geral de conduta? A lógica do intercâmbio é a negociação, a barganha para obtenção da maior vantagem (ou menor desvantagem), implicando a minimização dos meios dispendidos para a consecução desses fins. Instituir esse comportamento equivale a instaurar uma barganha generalizada, um sistema aberto de concorrência permanente entre inúmeros agentes econômicos, não obstante seus interesses individuais de maximização do ganho sejam mutuamente excludentes. Uma condição histórica tão peculiar requer condições iniciais bem particulares, além de medidas subsequentes para garantir que as novas regras do jogo econômico se consolidem e perpetuem. $\mathrm{Na}$ experiência ocidental moderna, essas condições foram as seguintes:

- Que nada se interpusesse na negociação, no cálculo dos preços de compra e venda, a não ser o livre-arbítrio das partes que transacionam, de acordo com o valor que atribuem aos bens e conforme estimem inexistirem alternativas melhores para o negócio. Diante de avaliações convergentes, o negócio tende a se concretizar e, sendo

9 A instituição da sociedade de mercado e suas consequências sociais nefastas constituíram o tema mais retumbante tratado por Karl Polanyi, havendo sido a perspectiva de sua superação histórica no período entre guerras, de retorno a uma situação de novo encaixe social da economia, o que ele considerou como a vindoura grande transformação. 
também essa a tendência provocada por uma sucessão de atos semelhantes, caminha-se, em tese, para um equilíbrio geral entre oferta e demanda (embora os fatos demonstrem uma instabilidade permanente do sistema). Nenhum artifício deve interferir, para não macular as bases racionais das negociações.

- Que todos ou que o maior número de bens pudesse ser transacionado nesse sistema, livre e a preços flutuantes. Isso inclui bens e fatores necessários à produção de outros bens, a exemplo de recursos naturais como a terra, ou da força de trabalho, convertida para todos os efeitos em mercadoria, com preço fixado pelo mercado de trabalho. Tudo sendo deixado ao sabor da lei da oferta e da procura, passa a ser racional que os agentes tracem estratégias competitivas, exponham-se a riscos e posicionem a escassez a seu favor, produzindo bens ainda pouco ofertados ou provocando a ampliação da demanda por diferentes estratagemas.

- Condições objetivas (materiais, tecnológicas, físicas) para produzir indefinidamente para o mercado, renovando a oferta de bens disponíveis e reduzindo os custos de produção: inovar em produtos sem elevar preços é uma estratégia segura para barganhar com sucesso; ganhos de escala são um requisito da acumulação geométrica do capital. Com o maquinismo, abriu-se não somente uma via possível, mas irreversível, para perpetuar esse mecanismo.

- Uma ação ideológica capaz de descredenciar ou demover os espíritos céticos ou recalcitrantes e consagrar a nova lógica econômica como superior, comparada aos "malfazejos artifícios" das economias protegidas e controladas. Isso, graças a um segmento considerável de agentes empenhados no funcionamento sempre mais aperfeiçoado dessas engrenagens, estando eles dotados de capital, poder político e coesão ideológica suficiente para impor tais diretivas, pelo sufrágio ou pela força, até sua instauração como padrão econômico instituído e dominante.

- Uma ação política orientada por esse novo credo, destinada a derrubar as barreiras jurídicas - formais ou baseadas na tradição - antepostas à liberdade e à expansão do mercado; portanto, tendo como objetivo vencer os movimentos de resistência e produzir um novo aparato legal-burocrático em prol do funcionamento desimpedido da nova economia. 
Como sabemos, esse é precisamente o cenário histórico de ascensão do capitalismo: a época da revolução industrial, dos ideais iluministas, da formação de novas classes, de embates políticos e ideológicos - mas também de dúvidas e perplexidades - ao lado de crenças nas virtudes da razão e nas perspectivas radiosas de progresso; uma época de instauração da sociedade burguesa e de sua contraface - a sociedade de mercado. Suas estruturas subordinaram-se gradativamente aos ditames da economia por meio de novas instituições, em substituição a estruturas e instituições anteriores, vistas daquele novo ponto de vista como tradicionais, anacrônicas e irracionais. Fundou-se uma sociedade em que as leis de mercado se impuseram progressivamente e converteram em mercadorias as mais diferentes necessidades e criações humanas - o que significou transferi-las ao domínio da propriedade privada para que pudessem ser alienadas livre e sucessivamente por atos de compra e venda.

O novo sistema econômico emancipou-se dos entraves sociais, culturais e jurídicos vigentes. As novas instituições tiveram por função ordenar o mercado e repelir diretivas estranhas à sua lógica; elas servem para compelir as trocas a seguirem as normas e o curso do mercado livre. Assim, a instituição do mercado passou a submeter as demais - pois na sua ótica representavam freios extraeconômicos -, abrindo campo ao seu desenvolvimento: livre mercado de trabalho, de terras, de recursos produtivos, de conhecimentos etc.

Em vez de a economia estar embedded nas relações sociais, são as relações
sociais que estão embedded no sistema econômico. A importância vital do fa-
tor econômico para a existência da sociedade obsta qualquer outro resultado.
Uma vez que o sistema econômico está organizado em instituiçôes separadas,
baseadas em motivos especificos e usufruindo de um status especial, a sociedade
tem que ser modelada de tal maneira que permita ao sistema funcionar de acordo
com suas próprias leis. Esse éo sentido da afirmação familiar de que uma econo-
mia de mercado pode funcionar apenas em uma sociedade de mercado (Polanyi,
2001, p. 60).10

No caso do mercado capitalista, o único que chegou à escala global, a lógica determinante das transações responde às exigências não apenas da liberda-

10 O vocábulo embedded, mantido aqui sem tradução, foi empregado por Karl Polanyi em sua obra seminal de 1944 apenas seis vezes (mas não os substantivos correlatos, embeddedness ou embedding, nem os antônimos disembedded ou disembedding, usuais entre os comentadores de sua obra). A palavra embedded pode ser traduzida em primeira mão como inserido ou embutido, preferencialmente a embebido (impregnated), utilizado às vezes em português. Encontrar um correlato satisfatório em nosso vernáculo não é fácil, tanto mais que o termo original possui diferentes conotações em inglês, em sentido físico e abstrato. A alternativa usual de traduzi-lo por inserido (e inserção) peca pela inespecificidade desse termo, enquanto a outra opção frequente, imbricado (e imbricação), remete, a nosso ver, mais à ideia de organização física. 
de de preços, mas do ciclo de acumulação constante do capital, por meio da circulação crescente de mercadorias; ou seja, de produtos do trabalho assalariado sobre o qual se realizou a extração de mais-valia e que, tanto quanto a própria força de trabalho, são transacionados segundo a mesma lei de formação dos preços. Por isso, ao contrário de sistemas de mercado (ou comércio) delimitados ou acessórios, a lógica capitalista desfaz as amarras sociais da economia nos mais diversos níveis e searas, tornando-se autotélica. Ela repele as coerções que lhe sejam estranhas e, seguindo sua racionalidade inerente, se transfere aos demais campos da vida social. Engendra, então, uma sociedade de mercado.

\section{A pluralidade econômica}

Isto posto em relação a esse episódio histórico, momentoso e ainda determinante de nossa época, convém não perder de vista que as economias reais derivam sempre de um processo que se define a partir das vias de integração de distintos princípios econômicos e das alternativas institucionais que encontrem. Empregando um ou mais princípios, as instituições conformam modelos ou padrões, cujo entrelaçamento com outros padrões concomitantes - e com seus princípios econômicos correlatos - dá lugar às formas históricas de economia. $\mathrm{O}$ acionamento de um mesmo princípio pode suscitar realidades empíricas ou modelos distintos de economia ainda que compartilhem a mesma lógica estruturante - em razão de circunstâncias históricas peculiares e, também, porque a existência de um padrão vinculado a um dado princípio econômico não implica o banimento dos demais, tampouco de padrões secundários. Sendo aceita a tese de que as economias reais se constituem de arranjos entre vários princípios, surgem diversas possibilidades, conforme o nível de análise em questão:

- Situações de hibridismo correspondem à combinação consistente e significativa de princípios econômicos (que perdem seu estado puro) em algum tipo de comportamento. $\bigcirc$ fato é ilustrado em nossos dias por relações econômicas ao mesmo tempo familiares e empresariais, o que gera constantes dilemas para a vida em família e a condução das empresas.

- A ocorrência de padrões mistos decorre das formas de economia instituídas, internamente heterogêneas do ponto de vista dos princípios que 
as determinam. É o caso dos mercados comunitários e de situações mais recentes, como os bancos éticos e as redes de comércio justo. A coexistência entre distintos princípios econômicos em seu modus operandi é um dos dilemas do setor cooperativo e, por extensão, da ESS.

- A pluralidade econômica, como tal, corresponde à coexistência de padrões no interior de um mesmo sistema econômico englobante, no qual um princípio e seu padrão correlato assumem um papel integrativo e uma função dominante sobre os demais. O fato é constatável nas formações econômicas em geral; sua natureza, eminentemente plural, contradiz o monismo e o evolucionismo imanentes às teses da onipresença, superioridade e universalismo do mercado.

A título de exemplo, consideremos o princípio de intercâmbio. Ele obedece a uma racionalidade instrumental de índole pragmática, que origina laços contratuais. Sua instituição configura, em cada tempo e lugar, um sistema de trocas em que vários agentes transacionam. Os mercados modernos caracterizam-se pela impessoalidade e pela monetarização, como bem ilustra a empresa capitalista. ${ }^{11}$ No entanto, a depender da ação paralela de outros agentes econômicos e da prevalência de outras lógicas, o espaço do mercado adquire outras conotações. Isso justifica a menção a mercados de reciprocidade, nos quais inexiste o pressuposto de uma equivalência monetária assegurada por cálculos utilitários de oferta e demanda (Sabourin, 2006, p. 21). Assim, ainda que estejam alinhados a um princípio diretor, os mercados e as práticas que orbitam à sua volta abrigam outros agentes e dão curso a lógicas concomitantes. Regra geral, mercados não configuram um espaço exclusivamente movido pelo interesse, por relações de intercâmbio ou pela lógica estrita da empresa capitalista.

Pode-se argumentar, todavia, que no mundo atual a economia tornou-se sinônimo de mercado e que esse funciona ditando soberanamente os critérios de participação dos consumidores, o que nos afasta da percepção do mercado como um espaço livre, de efetivação consentida de trocas em resposta a necessidades humanas. Ainda assim, vale insistir, o mercado comporta mais de uma aplicação da lógica própria ao intercâmbio. $\bigcirc$ ato de troca neutraliza essas nuances, mas o faz às vezes mais em aparência: a comercialização de um produto "made in" por uma franquia internacio-

11 A propósito, as diversas designações que as empresas capitalistas se outorgam - setor empresarial, setor produtivo, $1^{\circ}$ Setor, ou simplesmente mercado - deixam transparecer suas estratégias de imposição simbólica. 
nal, em um shopping center, pouco tem de substantivamente similar à venda de um artigo oriundo da produção mercantil simples em lojas locais de varejo ou em feiras de artesanato, ou à prestação de serviços a domicílio que envolvem proximidade interpessoal. Portanto, existem múltiplos mercados dentro do mercado, segundo a natureza e a motivação dos agentes que transacionam. Ademais, agentes atípicos atuam circunstancialmente no mercado, a partir de suas lógicas específicas: aquela de subsistência, voltada prioritariamente ao autoconsumo, participa das trocas quando the sobram excedentes e dispõe de meios de comercialização; a lógica comunitária, quando extrapola os ambientes próximos de circulação de bens; o Estado quando, agindo em prol do desenvolvimento socioeconômico, contrata serviços e produtos, lançando mão de princípios da economia pública aos quais devem - ou deveriam subordinar-se os agentes privados.

Passemos ao princípio da redistribuição, cujo domínio fundamenta-se na existência de um pacto em torno de prioridades coletivamente sancionadas, mesmo tacitamente, e no acato de uma autoridade central à qual raramente se aquiesce por obrigação estrita, despojada de qualquer vontade. Nas sociedades modernas, isso acarretou a ascensão de um aparato legal-burocrático sobre o qual se assenta a economia pública e seu principal agente - o Estado. O princípio da redistribuição também orienta organizações privadas, como aquelas sem fins eminentemente lucrativos, identificadas em alguns países com o espaço institucional do $3^{\circ}$ Setor, por oposição ao Estado e ao mercado. Agentes não estatais, atuando no campo da filantropia e da inclusão social, redistribuem recursos que lhes são doados voluntariamente ou sub-rogados pelo Estado, atuando como promotores de laços, mesmo entre pessoas anônimas, e como propagadores da reciprocidade social.

Como terceiro exemplo, quando um consumidor vai às compras em uma feira agroecológica, em geral desembolsa a quantia solicitada após transitar pelos estandes, comparando produtos e preços. Mas é improvável que o faça em função de uma presumida redução em seu dispêndio, mesmo quando a tenha estimado, sem também considerar que no ato de compra toma parte de um movimento em prol da alimentação saudável, da sustentabilidade do planeta, do sustento de agricultores exemplares ou, ainda, como forma de contestar os cartéis que dominam as cadeias globais de alimentos. Os vendedores, por sua vez, estão dispostos a "perder tempo", a entabular conversas com fregueses - e menos a barganhar com clientes anônimos. Entre os feirantes, em geral associados, há objetivos comuns 
e regras, há cooperação. Possivelmente, as ações de reconversão produtiva em que os agricultores se lançaram suscitam seu reconhecimento mútuo e motivam sua organização coletiva. Praticam-se atos de intercâmbio, entre compradores e vendedores, num ambiente determinado por motivações que destoam da supremacia do interesse próprio, o que estimula a camaradagem e suscita confiança. $O$ padrão desse microuniverso de comércio funda-se na reciprocidade, tanto pelo feitio peculiar das trocas econômicas entre feirantes e fregueses, quanto pelo espírito mais geral que os anima e os leva a tecer vínculos em prol de uma causa comum.

$\mathrm{Na}$ coexistência de vários princípios econômicos, portanto, repousam os fundamentos da economia plural (Laville, 2009; 2013). Motivações altruístas, para dar um último exemplo, podem explicar gestos de desprendimento, comuns no cotidiano das relações afetivas, valorizadas ritualmente em suas efemérides com doações mútuas (ou seja, presentes). Sua instituição, nesse caso, é confiada aos hábitos e à espontaneidade. Ao avançarmos para a órbita dos vínculos sociais entre grupos e organizações, em que despontam entidades associativas, confessionais e de classe, os atos passam a ser separados da simples rotina diária: eles ingressam em sistemas de reciprocidade para os quais concorrem também instituições originadas em outros princípios, a exemplo das deduções tributárias incidentes sobre doações filantrópicas ou de relevante interesse público. Contudo, doações podem também estar presas a uma dinâmica individual de autopromoção ou a objetivos empresariais de posicionamento no mercado, ficando à mercê dos dividendos auferidos utilitariamente. Portanto, à semelhança de inúmeros atos, os comportamentos altruístas combinam-se com vários princípios, que os instituem cada qual a seu modo, conferindo-lhes sentido e vigências singulares.

Voltando a Karl Polanyi (1957; 1968), um princípio torna-se integrativo ao originar instituições condizentes, aptas a materializá-lo e disseminá-lo. Assim, as formas instituídas em concreto não ficam indiferentes aos princípios. Nesse sentido, o elã cooperativo, essencial ao êxito e à perenidade das organizações da ESS, encontra o seu ambiente natural em padrões instituídos a partir da reciprocidade. Mesmo quando a gestão é orientada por requisitos de eficiência e otimização dos meios, instaurando laços contratuais entre seus membros, é um mister de sua viabilidade que preexistam ou se instaurem vínculos extraeconômicos, intangíveis, emuladores das condutas cooperativas nas quais radica o sentido e o valor da organização. Vínculos sociais motivam a participação e justificam renovados apor- 
tes dos integrantes da organização, a despeito de alternativas individuais eventualmente mais atrativas, sob um prisma utilitarista. As dificuldades enfrentadas pela ESS em ambientes dominados pelo mercado, além dos riscos que correm suas organizações, de desvirtuamento e absorção pela lógica do intercâmbio, têm a ver em boa medida com o fato de estarem fora de lugar. Como nos dizia Luis Razeto, com respeito às cooperativas:

\begin{abstract}
Esta vinculação do cooperativismo com o desenvolvimento capitalista deve ser entendida em termos dialéticos, para evitar uma errônea concepção - difundida em certos setores - que o critica por desenvolver-se "dentro do sistema" dominado pelo capital. Com efeito, o cooperativismo não é um fruto do capitalismo nem uma parte do mesmo, mas uma reação ante fenômenos sociais e econômicos derivados do capitalismo. Em relação ao modo de produção dominante, o cooperativismo apresenta-se como uma realidade subordinada, contraditória e alternativa (Razeto, 1990, p. 135).
\end{abstract}

Interpretar as economias reais a partir da imbricação entre princípios e lógicas não somente reflete fatos passados da nossa história com maior acuidade, como subverte a abordagem neoclássica das condutas econômicas, levando-nos a investigar outras motivações além do interesse próprio e outras esferas além da mercantil, bem como a discernir as condições sociais e políticas de primazia de um ou outro princípio, com seu padrão correlato. Pode-se então captar com amplitude os experimentos sociais que, na sua variedade, fogem ao monismo do individualismo contratual. Pode-se, ademais, vislumbrar a adoção de um sistema de regulação que garanta a coexistência de diferentes lógicas em condições mínimas de equilíbrio. Esse equilíbrio revitalizaria formas de economia vitimadas pela supremacia da economia mercantil, estimulando novos arranjos econômicos.

Uma configuração dessa ordem requer a existência de forças sociais vigorosas, orientadas por sua personalidade histórica, decorrente do modo como atuam no campo econômico e metabolizam no terreno político-ideológico as condições objetivas e subjetivas correspondentes. Em cada percurso ou momento histórico, caberia então inquirir as vias de preservação ou de instituição de princípios econômicos que caucionem outros padrões, socialmente vinculantes, no terreno de produção da vida material.

\title{
5 A função histórica da Economia Social e Solidária
}

A reciprocidade constitui um dos princípios econômicos que organizaram as práticas de produção e circulação de bens e serviços, tanto de peque- 
nos agrupamentos quanto de civilizações milenares, a exemplo dos Incas (Wachtel, 1974). Ao longo da história, ela se articulou com outros princípios, instituindo formas de economia híbridas e plurais (Polanyi, 1957; 1968; 1977). Para Karl Polanyi, convergindo com autores que relacionam a reciprocidade com o paradigma da dádiva ${ }^{12}$ (Sabourin, 2008, 2011a, 2011b), sua vigência como elemento integrativo não pode ser entendida sem o sistema de vínculos sociais em cujo arcabouço se insere. Isso a distingue da simples permuta bilateral ou de atos de intercâmbio generalizado:

O mesmo é verdade quando a reciprocidade é a regra; atos de permuta encontram-se aqui inseridos em relações de longo alcance implicando confiança e segurança, situação que tende a obliterar o caráter bilateral da transação. Os fatores limitantes surgem de todos os pontos do compasso sociológico: o costume e a lei, a religião e a magia contribuem igualmente para o resultado, que é o de restringir os atos de intercâmbio em relação a pessoas e objetos, tempos e ocasiões. Em regra, aquele que permuta apenas entra em um tipo de relação já determinado, no qual tanto os objetos quanto as quantias a eles equivalentes já estão dados (Polanyi, 2001, p. 64).

Como vimos, os mercados de reciprocidade e as feiras agroecológicas o demonstram, da mesma forma que as múltiplas formas de vida comunitária, as associações de produtores familiares ou as cooperativas de produção, crédito e serviços, fiéis ao ideário cooperativista. As retribuições que predominam nesses ambientes não separam riquezas materiais e espirituais em dois universos independentes, não se operam por uma equivalência ditada por critérios de mercado, não reduzem o seu significado ao firmado em contratos e, geralmente, não constituem compromissos individuais, mas sim prestações mútuas entre coletividades. Assim, a reciprocidade difere radicalmente da troca e se afasta de interesses utilitaristas. Organizações comunitárias típicas dos povos andinos ou dos campesíndios do México, assim como experiências associativas de magnitude levadas à frente em contextos rurais e urbanos de países como Canadá, França e Portugal, atestam a vigência da reciprocidade com esses sentidos (Gardin, 2006; Servet, 2013; Gaiger e Santos, 2017), mesmo quando as transações como tais

12 Há uma extensa bibliografia sobre o paradigma da dádiva, destacando-se autores antiutilitaristas que o consideram no contexto das sociedades contemporâneas (Caillé, 1996; 2000; Godbout, 1999). Marcel Mauss (2003) formulou o princípio da dádiva ao reunir e comparar uma imensidão de estudos e relatos etnográficos, concluindo ser ele um fundamento antropológico basilar das sociedades humanas. O cerne desse paradigma diz respeito a uma dinâmica tríplice de "dar-receber-retribuir", simbólica e ao mesmo tempo referida a uma ordem prática e política de reciprocidade, confiança e aliança. Em muitos casos históricos isso resultou na criação e no cultivo de vínculos sociais, apreensíveis no plano das relações interpessoais, entre agrupamentos e entre coletividades maiores, como povos e nações. 
dizem respeito a utilidades, valores éticos e laços sociais estão em jogo. Dentro do enfoque proposto, a reciprocidade é assim o princípio que espelha e permite compreender a dinâmica econômica a partir do espírito de cooperação e do sentido vinculante das organizações de ESS.

Mutatis mutandis, um dos papéis históricos relevantes da ESS é ter veiculado e materializado o princípio da reciprocidade, preservando-o como vetor de resistência e, ao mesmo tempo, de alternatividade, em sociedades duramente afetadas pela supremacia do intercâmbio e da lógica do mercado. Cumprindo esse papel, a ESS tem protegido sistemas de vida em que a economia se encontra socialmente embedded e, por isso, controlada em seu potencial destrutivo. Ela favorece a criação de novas alternativas, como aquelas hoje associadas em alguns países à Economia Solidária, como o Brasil. Até certo ponto, a ESS garante o hibridismo no interior dos mercados, matizando a tendência autotélica do intercâmbio e introduzindo variações no padrão de mercado. Por todas essas razões, como seu próprio nome indica, ela preserva laços sociais e revigora a solidariedade.

Esse enfoque requer algumas precisões conceituais, a bem de evitar mal-entendidos. Em primeiro lugar, muitas vezes a reciprocidade é compreendida apenas a partir de seu sentido comum, de gestos repetidos de retribuição bilateral, ou seja, como "uma relação mútua reversível entre dois sujeitos" (Sabourin, 2008, p. 137). Nessa acepção, de mecanismo tangível de troca e circulação de bens e serviços, a reciprocidade tem merecido atenção das ciências sociais e econômicas. Porém, ao se abstraírem os valores e os vínculos sociais que sustentam a reciprocidade, ela termina em muitos casos assemelhada a um tipo de "intercâmbio simétrico", o que induz à sua identificação com a regra de equivalência própria da troca (Sabourin, 2011a, p. 27). Ora, como vimos, em sua análise das trocas Karl Polanyi acentuou que, sob a reciprocidade, "os atos de permuta são geralmente inseridos em relações de longo alcance que implicam aceitação e confiança" (Polanyi, 2000, p. 81). A depender de si, a mera troca tende a encerrar uma reciprocidade mínima, sem envolver "valores afetivos ou éticos como a paz, a confiança, a amizade e a compreensão mútua" (Sabourin, 2008, p. 135). ${ }^{13}$

13 Essa identificação indevida entre reciprocidade, troca e equivalência, além de sua associação à obrigatoriedade de retribuir, motivou autores como Jacques Godbout a afastarem-se do conceito de reciprocidade: "O grande erro dos modelos baseados na reciprocidade é a confusão entre a constatação da retribuição e a vontade ou a intenção de retribuição" (Godbout, 2002, p. 88). 
Ao suprimirem-se essas diferenças substantivas, fica-se a um passo de classificar a reciprocidade como mais um estratagema de obtenção de ganhos, bem ao gosto da abordagem utilitarista, para a qual ações coletivas de cooperação são, em última instância, meios alternativos de realizar fins egoístas (Guerra, 2002, p. 165). Enquanto gestos repetidos de retribuição, a reciprocidade por certo é um mecanismo funcional - todos os princípios econômicos devem sê-lo, de algum modo - e por isso figura como prática corrente nas organizações que se pautam pela cooperação. No entanto, além disso, elas se guiam pelo princípio da reciprocidade. Como vetor fundante, o que está em jogo na reciprocidade são questões de mútuo reconhecimento, de preservação de identidades coletivas, de protagonismos em nome de valores e de um horizonte comum. A coexistência entre esses dois níveis de reciprocidade, aliás, foi apontada por Karl Polanyi a respeito das Ilhas Trobiand, local em que os estudos antropológicos trouxeram à tona o ciclo da dádiva de "dar-receber-retribuir" (Mauss, 2003), chave para a perpetuação dos vínculos sociais: de um lado, uma reciprocidade prática relacionada à subsistência cotidiana, por meio de um esquema sofisticado de ajuda entre as famílias de cada núcleo insular; de outro lado, uma reciprocidade simbólica, envolvendo um amplo circuito de prestações cerimoniais entre as ilhas - o Kula - num trabalho imenso e incansável visando "minimizar a rivalidade e o conflito, e maximizar a alegria de dar e receber presentes"; com isso, preservando a aliança e a paz (Polanyi, 1977, p. 51).

Ao escrutinar um conjunto amplo de iniciativas estruturalmente similares àquelas da ESS, no contexto europeu, um estudo concluiu que muitas delas se valem em sua fase de arranque de aportes materiais, humanos e técnicos oriundos tanto de subvenções públicas quanto de doações ou do trabalho voluntário, além das vendas no mercado. Elas se sustentam em um híbrido de recursos (Gardin, 2006, p. 77-78). Na etapa de consolidação, no entanto, cabe à reciprocidade jogar o papel principal, vindo a dar novos sentidos às relações de intercâmbio dessas organizações. Criam-se formas de reciprocidade entre pares (entre feirantes, no exemplo anterior) ou multilateral (caso do comércio justo), quando envolvem participantes de variados extratos, de trabalhadores a apoiadores benemerentes, comprometidos com o sentido social das iniciativas e com sua índole democrática e igualitária (Gardin, 2006, p. 54-55). ${ }^{14}$ O papel fulcral da reciprocidade 14 Para Laurent Gardin (2006, p. 62), "a reciprocidade multilateral aparece como o ideal-tipo das iniciativas solidárias e se manifesta em organizações que não buscam a maximização do 
revela-se no grau de envolvimento dos participantes - motivados mais pelos laços sociais do que pelos bens materiais - nas considerações éticas e políticas (direitos humanos, natureza, paz) subjacentes à escolha das estratégias dessas organizações e, sobretudo, na função basilar dos aspectos relacionais, de cultivo de vínculos interpessoais duráveis (Gardin, 2006, p. 152-158 et passim).

Desfazendo um segundo foco de mal-entendidos, diante disso tornam-se compreensíveis os casos de "reciprocidade não igualitária" destacados pelo mesmo autor (Gardin, 2006, p. 48-50), no tocante a iniciativas de solidariedade em que os beneficiários da ação, desprovidos de recursos mínimos, mal podem retribuir com gestos, embora seja imaginável que possam fazê-lo em atitude, subjetivamente. $O$ problema nesses casos não seria a ausência de retribuição, mas sim a falta de vontade de retribuir. Caso a simetria fosse requisito prévio estrito, exigindo desde o início uma efetiva "reciprocidade entre pares" (Gardin, 2006, p. 50-55), em sociedades como as nossas esse princípio do agir teria bem menos viabilidade, a começar pela enorme dificuldade de instaurar-se. Assim, convém que a reciprocidade seja vista como um princípio social e econômico latente, inserido em uma dinâmica vinculante, funcionando como esteio de relações de cooperação e de solidariedade correlatas.

\section{Considerações finais}

Além dos argumentos apresentados, quais boas razões existiriam para que princípios vinculantes, como a reciprocidade, tenham futuro nos dias de hoje? Em primeiro lugar, para alguns autores, na medida em que uma das transformações fundamentais promovidas pela cultura moderna reside no valor conferido à autonomia individual, esse novo ambiente pode favorecer não o aniquilamento do ciclo vinculante da dádiva, como se poderia crer, mas antes a sua transposição da esfera das relações interpessoais impositivas (família, agremiações fechadas) para o âmbito das relações grupais abertas, formadas por livre adesão. Conforme recorda Philippe Chanial (2001, p. 142), um dos equívocos cometidos pelo pensamento liou mesmo contribuintes em capital e poderes públicos), colocados em relações simétricas e igualitárias." 
beral consistiu em ver na instauração da democracia moderna um simples movimento em direção ao individualismo, uma tendência de liberar os seres humanos dos laços que os uniam a seus semelhantes. Na verdade, a ruptura da arquitetura social precedente, com suas corporações e ordens hierárquicas de filiação adstrita, deu lugar à formação de novas e variadas associações já não mais compulsórias, mas voluntárias, flexíveis e abertas. Essa inclinação foi evidenciada justamente pela emergência do movimento associativo, cooperativo e mutualista, assim como pela multiplicação de sindicatos, partidos políticos, corporações industriais, organizações científicas, clubes etc. - um fato, por sinal, assinalado por Marcel Mauss (2003, p. 294-301). Se o Estado-nação é o espaço moderno de contração de "vínculos societais" (Gaiger, 2016, p. 113), o Estado democrático apresenta-se, em que pesem as derivas provocadas pelo utilitarismo e pela sociedade de mercado, como uma ampla associação voluntária de cidadãos.

Em segundo lugar, a reciprocidade fundamenta-se na ideia de interdependência, no cuidado com o outro, na aliança entre gerações que se encadeiam umas às outras (Servet, 2013, p. 199). Ao promover vínculos a partir do terreno econômico, a reciprocidade os transfere dos circuitos primários à órbita da sociabilidade secundária, sem incorrer em despersonalização e alienação. Além disso, ela a transcende para órbitas ainda mais alargadas, próprias da sociabilidade terciária hoje impulsionada pela interconectividade da "sociedade virtual mundializada" (Caillé, 2000, p. 136). Nessas transições, a reciprocidade supera os limites da incondicionalidade própria às estruturas sociais elementares, favorecendo o equilíbrio entre liberdade, autonomia e segurança. Além de propiciar um retorno renovador aos circuitos primários, tais confluências representam atualmente uma contribuição primordial das organizações baseadas no associativismo e na solidariedade. No campo das ações humanitárias, as organizações civis tendem a aproximar doadores e receptores, a personificar a figura dos beneficiários, evitando desvios, ineficiência e desperdícios dos recursos (Godbout, 1999, p. 76). Ao acompanharem a ação estatal, tais iniciativas evitam que a ação dos aparelhos burocráticos privilegie unilateralmente critérios de funcionalidade e de padronização que esmaecem o sentido das políticas públicas de redistribuição ou de promoção de agentes econômicos, entre outras. No âmbito da democracia, trata-se de resgatar o princípio da aliança para reconstituir o político como instância racional de deliberação e de exercício legítimo do poder; ato contínuo, de regenerar as instituições políticas inca- 
pazes de absorver e gerir as diferenças e antagonismos próprios de sociedades plurais, tendo-se ciência da necessidade de preservar e interligar a socialidade primária, secundária e terciária, coexistentes na sociedade global.

Em terceiro lugar, e não obstante o exposto acima, vale reiterar que, na sua origem, a dádiva e a reciprocidade não foram concebidas como acontecimentos humanos pretéritos. Embora as elaborações seminais a seu respeito - de Marcel Mauss e Karl Polanyi - provenham em grande medida de estudos etnográficos sobre as ditas sociedades arcaicas, conduzindo Karl Polanyi a associar a reciprocidade a uma estrutura de "grupos de parentesco" simetricamente ordenada, não se trata de uma lógica restrita a sociedades perdidas no tempo, das quais restariam apenas reminiscências e ensinamentos morais. Organizações movidas pela reciprocidade são, como argumentamos, de fácil exemplificação atualmente, inclusive no âmbito da economia globalizada, o que fica patente em tratados internacionais de comércio (Sabourin, 2006; 2011a). Karl Polanyi em pessoa sublinhara: "De forma alguma deve-se concluir que os princípios socioeconômicos desse tipo são restritos a produtores primitivos ou pequenas comunidades, e que uma economia sem lucro e sem mercado deve ser simples, necessariamente" (Polanyi, 2000, p. 69).

Conjugadas, as obras desses dois autores elucidam condutas persistentes ao longo do tempo - como a responsabilidade e o cuidado entre gerações que hoje se transladam para a sustentabilidade e o futuro do planeta. Ambos extraíram conclusões morais e políticas de seus estudos, indicando o caráter providencial dos vínculos de solidariedade existentes nos circuitos de redistribuição a cargo da economia pública, como no exemplo notório da previdência social - fato hoje obscurecido pela racionalidade tecnocrática do Estado (Nanteuil, 2014) e pelas incessantes pressões para que os ativos e as reservas destinadas ao bem-estar futuro das populações ingressem no circuito inclemente da mercadoria. Tem-se então um arcabouço teórico e conceitual sólido e fecundo para considerar a pluralidade da economia contemporânea, com seus diversos padrões institucionais, sem deixar-se levar pela crença no determinismo econômico e pela obsessão do mercado (Polanyi, 1947a; 1947b). É desse ponto de vista, tendo consciência dessas falácias e da impropriedade de situar a ESS nos mesmos termos da lógica competitiva do mercado, que convém dimensionar sua relevância histórica e compreender os desafios que ela tem enfrentado com suas diversas concepções, modelos e práticas. 


\section{Referências}

ARENSBERG, C.; PEARSON, H.; POLANYI, K. Trade and Markets in the Early Empires. Economies in History and Theory. Glencoe: The Free Press, 1957.

CAILLÉ, A. Ni holisme ni individualisme méthodologique. Marcel Mauss et le paradigme du don. Revue du MAUSS Semestrielle, v. 8, p. 12-58, 1996.

CAILLÉ, A. Anthropologie du don. Le tiers paradigme. Paris: Desclée de Brouwer, 2000.

CATTANI, A.; GAIGER, L.; HESPANHA, P.; LAVILLE, J.-L. (Org.). Dicionário internacional da outra economia. Coimbra: Almedina, 2009.

CHANIAL, P. Société civile, société civique? Associationisme, libéralisme et républicanisme. In: LAVILLE, J.-L.; CAILLÉ, A.; CHANIAL, P. Association, démocratie et société civile. Paris: La Découverte, p. 141-161, 2001.

DEFOURNY, J.; NYSSENS, M. (Dir.). Économie sociale et solidaire. Socioéconomie du 3 o secteur. Louvain-la-Neuve: De Boeck Supérieur, 2017.

GAIGER, L. A descoberta dos vínculos sociais: os fundamentos da solidariedade. São Leopoldo: Unisinos, 2016.

GAIGER, L.; SANTOS, A. (Org.). Solidariedade e ação coletiva; trajetórias e experiências. São Leopoldo: Unisinos, 2017.

GAIGER, L.; NYSSENS, M.; WANDERLEY, F. (Ed.). Social Enterprise in Latin America: Theory, Models, and Practice. New York: Routledge, 2019.

GARDIN, L. Les initiatives solidaires. La réciprocité face au marché et à l'état. Ramonville SaintAgne: Éditions Ères, 2006.

GODBOUT, J. O espírito da dádiva. Rio de Janeiro: Fundação Getúlio Vargas, 1999.

GODBOUT, J. Homo donator versus homo oeconomicus. In: MARTINS, P. (Org.). A dádiva entre os modernos. Discussão sobre os fundamentos e as regras do social. Petrópolis: Vozes, 2002. p. 63-97.

GRANOVETTER, M. Economic Action and Social Structure: The Problem of Embeddedness. American Journal of Sociology, v. 91. n. 3, p. 481-503, 1985.

GRANOVETTER, M. Coase Encounters and Formal Models: Taking Gibbons Seriously. Administrative Science Quarterly, n. 44, p. 158-162, 1999.

GRASLIN, L.; MAUCOURANT, J. Le port de commerce: un concept en débat. Topoi, Orient Occident, n. 12-13, p. 216-257, 2005.

GUERRA, P. Socioeconomía de la solidaridad. Montevideo: Editorial Nordan-Comunidad, 2002.

LAVILLE, J.-L. Le renouveau de la sociologie économique. Cahiers Internationaux de Sociologie, n. CIII, p. 229-235, 1997.

LAVILLE, J.-L. Economia plural. In: CATTANI, A.; GAIGER, L.; HESPANHA, P.; LAVILLE, J.-L. (Org.). Dicionário internacional da outra economia. Coimbra: Almedina, p. 145-149, 2009.

LEVINE, A.; SOBER, E.; WRIGHT, E. Marxismo e individualismo metodológico. Revista Brasileira de Ciências Sociais, v. 4, n. 1, p. 57-70, 1989.

MAUCOURANT, J.; PLOCINICZAK, S. L'«institution» selon Karl Polanyi. Fondements et 
mise en perspective contemporaine. Tracés - Revue de Sciences humaines, 2009. Disponível em: <http://traces.revues.org/4257>. Acesso em: 11 out. 2019.

MAUSS, M. Sociologia e antropologia. São Paulo: Cosac Naify, 2003.

MULGAN, T. Utilitarismo. 2. ed. Petrópolis: Vozes, 2014.

NAMORADO, R. Cooperativismo: história e horizontes. Estudos de Direito Cooperativo e Cidadania, n. 1, p. 9-35, 2007.

NANTEUIL, M. Socialismo y emancipación en el siglo xxi: la cuestión de la solidaridad. In: CORAGGIO, J.; LAVILLE, J.-L. (Ed.). Reinventar la izquierda en el siglo XXI: hacia un dialogo norte-sur. Los Polvorines: Universidad Nacional de General Sarmiento, 2014. pp. 397-407.

PEARSON, H. The Economy has no Surplus: Critique of a Theory of Development. In: ARENSBERG, C.; PEARSON, H.; POLANYI, K. Trade and Markets in the Early Empires. Economies in History and Theory. Glencoe: The Free Press, 1957. p. 320-341.

POLANYI, K. On Belief in Economic Determinism. Sociological Review, v. 39, n. 1, p. 96-112, 1947a.

POLANYI, K. (1947b). Our Obsolete Market Mentality. Commentary, v. 3, n. 2, p. 109-117, $1947 b$.

POLANYI, K. The Economy as Instituted Process. In: ARENSBERG, C.; PEARSON, H.; POLANYI, K. Trade and Markets in the Early Empires. Economies in History and Theory. Glencoe: The Free Press, 1957. p. 243-270.

POLANYI, K. Ports of Trade in Early Societies. The Journal of Economic History, v. XXIII, n. 1, p. 30-45, 1963.

POLANYI, K. Primitive, Archaic and Modern Economies: Essays of Karl Polanyi. New York: Anchor Books, 1968. (Edited by DALTON, G.).

POLANYI, K. The Livelihood of Man. New York: Academic Press, 1977. (Edited by PEARSON, H.).

POLANYI, K. A grande transformação. As origens da nossa época. 2. ed. Rio de Janeiro: Campus, 2000 [1944].

POLANYI, K. The Great Transformation: The Political and Economic Origins of our Time. 3. ed. Boston: Beacon Press, 2001 [1944].

POLANYI, K. Textos escogidos. Buenos Aires: Altamira, 2012. (Editado por CORAGGIO, J.).

RAUD-MATTEDI, C. A construção social do mercado em Durkheim e Weber. Análise do papel das instituições na sociologia econômica clássica. Revista Brasileira de Ciências Sociais, v. 20 , n. 57 , p. $127-142,2005$.

RAZETO, L. Las empresas alternativas. Montevideo: Editorial Nordan-Comunidad, 1990.

SABOURIN, E. A qualificação das transações econômicas: aportes e limites da contribuição de Karl Polanyi. In: ENCONTRO ANUAL DA ANPOCS. 30, Caxambu [GT 23 - Sociologia Econômica], 2006.

SABOURIN, E. Marcel Mauss: da dádiva à questão da reciprocidade. Revista Brasileira de Ciências Sociais, v. 23, n. 66, p. 131-138, 2008.

SABOURIN, E. Teoria da reciprocidade e socioantropologia do desenvolvimento. Sociologias, 
v. 13 , n. 27 , p. 24-51, 2011a.

SABOURIN, E. Sociedades e organizações camponesas: uma leitura através da reciprocidade. Porto Alegre: Editora da UFRGS, $2011 b$.

SEN, A. Sobre ética e economia. São Paulo: Companhia das Letras, 1999.

SERVET, J.-M. Le principe de réciprocité aujourd'hui. Un concept pour compreendre et construire l'économie solidaire. In: HILLENKAMP, I.; LAVILLE, J.-L. (Ed.). Socioéconomie et démocratie: l'actualité de Karl Polanyi. Toulouse: Eres, 2013. p. 187-213.

STIGLITZ, J. Foreword. In: POLANYI, K. The Great Transformation: The Political and Economic Origins of our Time. 3. ed. Boston: Beacon Press, 2001. p. vii-xvii.

WACQUANT, L.; CALHOUN, C. Interesse, racionalidade e cultura. Revista Brasileira de Ciências Sociais, ANPOCS, São Paulo, v. 6, n. 15, p. 76-93, 1991.

WACHTEL, N. La réciprocité et l'État inca: de Karl Polanyi à John V. Murra. Annales. Économies, Sociétés, Civilisations, v. 29, n. 6, p. 1.346-1.357, 1974.

\section{Sobre o autor}

Luiz Inácio Germany Gaiger-gaiger@unisinos.br

Universidade do Vale do Rio dos Sinos - Programa de Pós-Graduação em Ciências Sociais, São Leopoldo, RS, Brasil. ORCID: https://orcid.org/0000-0003-0241-7064.

\section{Sobre $o$ artigo}

Recebido em 11 de outubro de 2019. Aprovado em 22 de setembro de 2020. 